\title{
Maintenance of clonal diversity in Dipsa bifurcata (Fallén, 1810) (Diptera: Lonchopteridae). I. Fluctuating seasonal selection moulds long-term coexistence
}

\author{
M Niklasson ${ }^{1}$, J Tomiuk ${ }^{2}$ and ED Parker $\mathrm{Jr}^{1}$ \\ ${ }^{1}$ Department of Ecology and Genetics, Århus University, Ny Munkegade, Building 540, DK 8000 Århus C, Denmark; ${ }^{2}$ Division of \\ General Human Genetics, Institute of Human Genetics, University of Tübingen, Wilhelmstrasse 27, D-72074 Tübingen, Germany
}

\begin{abstract}
The deterministic maintenance of clonal diversity in thelytokous taxa can be seen as a model for understanding how environmental heterogeneity both can stabilize genetic diversity and can allow coexistence of competing species. We here analyze the temporal fluctuations in clonal diversity in the thelytokous Lonchopterid fly, Dipsa bifurcata (Fallén, 1810), at four localities in Sweden over an 8-year period. Estimated fitness values for clones are cyclical, synchronous among populations and correlated with seasonal changes in the environment. Differential winter viability and emergence from overwintering along with differential reproductive rate during the summer appear to be the selective mechanisms
\end{abstract}

by which long-term clonal diversity is maintained. In a companion paper (Tomiuk et al, 2004), we present a model for the maintenance of clonal diversity through the mechanism of differential diapause among clones, utilizing fitness values estimated from the data presented here. In general, our results imply that fluctuating seasonal fitnesses can maintain stable genetic polymorphism within populations, as well as coexistence between closely related competitors, when coupled with differences in diapause phenology.

Heredity (2004) 93, 62-71, advance online publication, 19 May 2004; doi:10.1038/sj.hdy.6800480

Keywords: clonal diversity; clonal coexistence; species coexistence; cyclical selection

\section{Introduction}

From a population genetic perspective, genetic diversity in female parthenogenetic (or thelytokous) taxa can be studied as a simple model for examining the maintenance of genetic polymorphism. From an ecological viewpoint, the mechanisms determining the number of and interactions among sympatric thelytokous lineages (or clones, see below) can be seen as a limiting case for the study of niche subdivision of coexisting species (Parker, 1979; Vrijenhoek, 1979; Hebert and Crease, 1980; Jaenike et al, 1980).

We here describe long-term dynamics of clonal diversity in Swedish populations of the thelytokous spearwinged fly, Dipsa bifurcata (Fallén, 1810) (Diptera: Lonchopteridae). Specifically, we analyze the temporal fluctuations in diversity and estimate fitness values from oscillations in clone frequencies at four localities in southern Sweden over an 8-year period. We show that these changes are cyclical, synchronous among populations in the same area and correlated with seasonal changes in the environment. In a companion paper (Tomiuk et al, 2004), we present a model for the maintenance of clonal diversity through the mechanism of differential diapause among clones, utilizing fitness

Correspondence: ED Parker Jr, Department of Ecology and Genetics, Arrhus University, Ny Munkegade, Building 540, DK 8000 Århus C, Denmark. E-mail: dave.parker@biology.au.dk

Received 3 July 2003; accepted 17 March 2004; published online 19 May 2004 values estimated from the data presented here. Taken together, our results strongly imply that fluctuating seasonal fitnesses among sympatric clones in a multivoltine species can maintain stable genetic diversity when coupled with clonal differences in diapause phenology.

The temporal variation in D. bifurcata is reminiscent of the classical studies of chromosome inversion dynamics in Drosophila pseudoobscura Frolova (Diptera; Drosophilidae) (cf, Dobzhansky, 1943; Anderson et al, 1975). However, in Drosophila, and all sexual species, inversion polymorphism can be maintained at least in part by heterozygote advantage, whereas in parthenogens, this form of selection cannot act as a factor maintaining polymorphism. The reason for this is that the transition to parthenogenetic reproduction alters both the unit of selection and transmission (Templeton, 1982). Hence, constant selection for heterozygosity, which would maintain polymorphism in bisexual species, would simply lead to fixation of the most heterozygous clone in a diverse thelytokous taxon. Instead, the deterministic maintenance of polymorphism (or, more appropriately, diversity) in asexual taxa requires genotype by environment interaction in fitness among genotypes and/or negative frequency dependent selection.

Both spatial and temporal heterogeneity in the environment have been suggested as possible factors promoting the maintenance of clonal diversity in natural populations (see Sebens and Thorne, 1985) and many excellent examples of spatial or trophic differences in clonal ecology have been documented (Vrijenhoek, 1978; 
Mitter et al, 1979; Christensen et al, 1988; Jokela et al, 1997; Weeks and Hoffmann, 1998), along with some studies showing long-term changes in clone frequencies in natural populations (Christensen and Noer, 1986; Dybdahl and Lively, 1998). Additionally Hebert and Ward (1976), Ochman et al (1980), Carvalho and Crisp (1987), Rossi and Menozzi (1990), and Weeks and Hoffmann (1998) have all documented seasonal changes in clone frequencies within populations of obligate thelytokes. However, to our knowledge, there have been no studies in which both the within- and between-year dynamics of clonal diversity and fitness have been studied in replicate populations of an obligate parthenogen over more than two yearly cycles. It is thus impossible to assess from these previous studies how stable the clone frequencies and their seasonal oscillations are through time.

In cyclical parthenogens, seasonal fluctuations in genotype frequencies are expected since the mictic phase will reshuffle the genetic variation in the population and the following parthenogenetic generations will be exposed to strong selection among genotypes (see also Annest and Templeton, 1978; Tomiuk and Wöhrmann 1981; Lynch and Gabriel, 1983). Hence, the fluctuation in genotype frequencies in species with this genetic system reflects the cyclical shift in mode of reproduction and the accompanying release of variation, as well as clonal selection. However, in obligate parthenogens, oscillatory changes in clone frequencies are a direct reflection of the changes in selection pressures acting on the individual multilocus genotypes in a seasonally heterogeneous environment.

\section{Materials and methods}

\section{The species}

Thelytokous populations of the spearwinged fly $D$. bifurcata are cosmopolitan in north and south temperate habitats. Bisexual populations of D. bifurcata are currently restricted to high latitude or high altitude climax grassland and bog habitats in a scattered pattern (northern Great Britain, Vestmann Islands off the coast of Iceland, the Atlas Mountains of North Africa and the Himalayas), reflecting a relictual distribution caused by different glaciations (Stalker, 1956; Andersson, 1970, 1983; Coulson and Butterfield, 1982). The closest bisexual populations to our study sites are in northern Great Britain and we consider it highly unlikely that the cyclical fluctuations seen in our Swedish thelytokes can be due to recruitment of clones from the bisexual race. This is because the same set of common clones have persisted throughout the course of this study and recruitment of newly originated thelytokes would have been identified by the sudden appearance of unique clones, which has not been observed in our data. Additionally, Dipsa are pitifully poor flyers, spending most of their adult lives crawling through vegetation (Niklasson, pers. obs.), making it unlikely that they are capable of rapid long distance dispersal.

The thelytokous race reproduces by automixis. Diploidy is restored by central fusion and crossing-over during meiosis is prevented by overlapping chromosome inversions, which are also polymorphic among clones. Hence, the offspring of a fly will be genetically identical to each other and to their mother, barring mutation, chromosomal nondisjunction and rare doublecrossovers inside inversion loops (Stalker, 1956; Asher, 1970; Ochman et al, 1980). In Sweden, the flies are generally found on cultivated grassland or lawns and are active from March until October. The number of generations is usually two, with progeny from overwintering flies emerging in midsummer and producing a second generation which then overwinters as adults or larvae (Coulson and Butterfield, 1982). In the lab at $20^{\circ} \mathrm{C}$, egg to adult development time is about 40 days and the adult lifespan is about 75 days (Baud, 1973).

\section{Sampling}

Four localities in the south of Sweden (province of Scania) were periodically sampled in the periods from 1981 to 1983 and 1986 to 1988 (Figure 1). Locality 1, Barkakra, is a grass lawn at the airport, ca $4 \mathrm{~km}$ from the west coast (Øresund). The lawn is mowed frequently and is surrounded by dry meadows, fields and asphalt surfaces. Locality 2, Ljungbyhed, is the verge of a football field just outside the village, $34 \mathrm{~km}$ from the west coast. The verge is mowed at irregular intervals and is surrounded by the football field, arable fields and pastures. Locality 3, Stenshuvud, is a pasture, sometimes used as a parking lot and $2 \mathrm{~km}$ from the east coast (Baltic Sea) and surrounded by woods and other pastures. It is never mowed. Locality 4, Smygehamn, is a public lawn in the harbor, ca $0.2 \mathrm{~km}$ from the south coast (Baltic Sea) and surrounded by fields and pastures. It is mowed frequently in the summer.

Sampling was performed at approximate 1 month intervals during the growing season, beginning in July 1981 to October 1981and April 1982 to October 1982. In 1983, samples were taken only in May, early June ('spring' samples for this year, see below) and August ('autumn' sample for this year). Sampling was again initiated from April to October 1986, July to October 1987 and May to October 1988. Flies were collected by sweep netting (500 sweeps) through the vegetation over an area

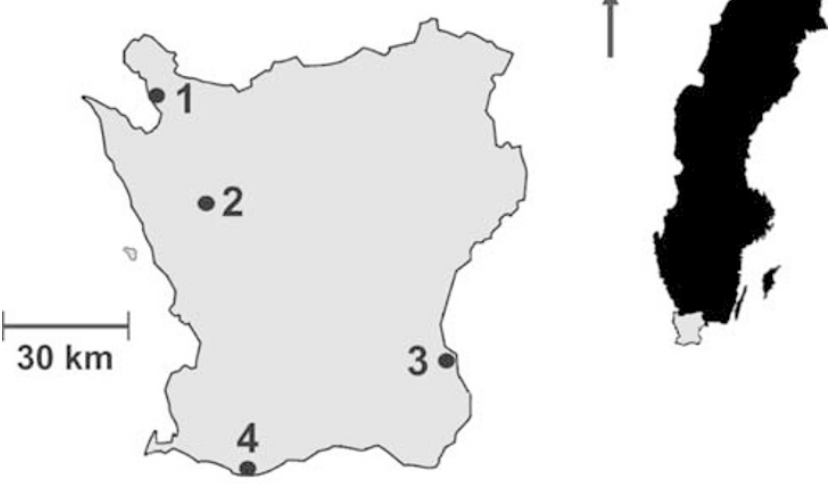

Figure 1 Map showing the province of Scania in southern Sweden and the four populations sampled in this study. Locality 1 Barkåkra (longitude: $012^{\circ} 51^{\prime} 18^{\prime \prime} \mathrm{E}$, latitude: $56^{\circ} 17^{\prime} 28^{\prime \prime} \mathrm{N}$ ); locality 2 Ljungbyhed (longitude: $13^{\circ} 13^{\prime} 00^{\prime \prime} \mathrm{E}$, latitude: $56^{\circ} 04^{\prime} 00^{\prime \prime} \mathrm{N}$ ); locality 3 - Stenshuvud (longitude: $014^{\circ} 17^{\prime} 00^{\prime \prime} \mathrm{E}$, latitude: $55^{\circ} 40^{\prime} 00^{\prime \prime} \mathrm{N}$; locality 4 - Smygehamn (longitude: $013^{\circ} 23^{\prime} 00^{\prime \prime} \mathrm{E}$, latitude: $55^{\circ} 20^{\prime} 46^{\prime \prime} \mathrm{N}$ ). Scale bar for Scania equals $30 \mathrm{~km}$. 
of approximately $200 \mathrm{~m}^{2}$. The same limited area at each locality was swept during each collecting trip. All localities were sampled within a few days of each other; however, flies were not collected at all localities during each trip due to inclement weather conditions. The data are therefore too unbalanced for a monthly or bimonthly comparison of each locality.

In order to contrast the four localities in a uniform way, we pooled all flies collected prior to 22 June in a particular year and locality as 'Spring' collections and all flies collected after this date as 'Autumn' collections. This simplification reflects the bivoltine reproductive cycle in this species in Sweden and allows us to contrast between five and seven seasonal transitions in clonal frequencies for each population (see Appendix B, below). Also, this pooling of the data has the conservative effect of 'averaging' spring vs autumn samples of flies, which should eliminate outlying estimates of clonal diversity or frequency due to special effects of bad weather, such as a lack of flies or small sample sizes. The first flies collected in April are melanized and have worn wings, reflecting their overwintering; by May-early June, lighter flies with complete wings dominate the collections, reflecting the emergence of flies that overwintered as larvae and/or progeny of the earliest active flies.

\section{Electrophoresis}

Clonal affiliation was determined by starch gel allozyme electrophoresis using two diagnostic loci, phosphoglucomutase (PGM, EC\# 5.4.2.2) and alkaline phosphatase (APH, EC\# 3.1.3.1), both monomeric in their phenotypic expression. Initially, 17 protein loci were tested, but most were monomorphic and PGM and APH together accounted for over $95 \%$ of the detected clonal variants (Niklasson, 1995). There were three PGM phenotypes, scored as MS, SS and MM, for the mobilities of two different gene products (alleles) present in these diploid thelytokes. APH revealed phenotypes consistent with different combinations of two of three different alleles, and five different clonal phenotypes were recognized, FF, FM, MM, MS and SS. No individuals having $\mathrm{APH}$ genotype FS were detected. Combined two-locus genotypes revealed 11 different clonal lineages in our data. A maximum of eight of these was detected in a single population, but only four genotypes were present in all populations. These we designate as clones A-D (see next paragraph, below), in descending order of their overall frequencies. The combined frequency of the remaining seven clones was 0.025 and, if any were present in a sample, their contribution to diversity estimates were pooled (see section below - Statistics and Analysis and Appendix A). Both enzymes were resolved on a discontinuous buffer system with a $0.1 \mathrm{M}$ Tris, $0.005 \mathrm{M}$ citrate gel buffer, $\mathrm{pH} 8.7$, and a $0.3 \mathrm{M}$ Borate tray buffer, pH 8.2 (Poulik, 1957), electrophoresis technique as described by Niklasson (1995) and Ochman et al (1980).

Confusion over the use of the term 'clone' to describe all individuals that carry a common multilocus genotype in an asexual taxon has been discussed ably by Lushai and Loxdale (2002). There are two definitions that deal with the term as it applies to individuals (as opposed to DNA fragments or specialized cell types, such as plasma cells). A clone is either '(1) a group of genetically identical individuals or cells derived from a single cell by repeated asexual divisions;...' or '(3) animal or plant derived from a single somatic cell or cell nucleus is termed a clone of the individual from which the cell or nucleus came...' (Lawrence, 2000, p 117; italics added). Note that the first of these explicitly identifies genetic identity as the distinguishing characteristic of clones, while the second refers simply to a lineage derived from a single ancestor. Our usage of the term here is closer to the second definition. Certainly, any single round of replication of substantial amounts of DNA (as in a eukaryote oogenesis) will generate mutation, and given enough marker loci, one can identify every individual as a different multilocus genotype. Our interest is in lineages that have substantial genetic (and, hopefully, ecological) differences from each other and that remain in natural populations for extended numbers of generations, without recombining with other such lineages. We call these lineages clones, in keeping with the definition above.

\section{Statistics and analysis}

Clonal diversity for each locality/season sample was calculated according to Simpson's (1949) measure of concentration, $C=\Sigma p_{i}^{2}$, where $p_{i}$ is the frequency of the $i$ th clone in the sample. $D=1-C$ is equivalent to sample gene diversity and simply reflects the probability of drawing two different clones at random from a population with the given frequencies (Nei, 1987). The reciprocal of $C$ is analogous to the effective number of genotypes (clones) in the sample (Kimura and Crow, 1964). The limiting minimum value of $C$ (and the maximum of $D$ ) is dependent on the actual number of clones present, so comparisons of taxa or populations with different numbers of clones should be adjusted by use of redundancy or evenness statistics (Fager, 1972; Parker, 1979). Since all our samples have four clones (or five, pooling any rare clones as a single category), such an adjustment is not necessary and we here use simple $D\left(=1-\Sigma p_{i}^{2}\right)$ as our measure of diversity. In analyses of variance on diversity, values were transformed to radians by the square root of the arcsin of $D$.

The performances (or 'fitnesses', sensu latu) of the clones were calculated as the ratios of their frequencies in two successive sampling periods (Manly, 1985): $w_{i}$ winter $=\left(p_{i} \text { spring }_{2} / p_{i} \text { autumn }\right)_{1}$, and $w_{i}$ summer $=\left(p_{i}\right.$ autumn $_{1} / p_{i} \quad$ spring $\left._{1}\right)$, where the $p_{i}^{\prime} \mathrm{s}$ are the clone frequencies in a sample and the seasonal indices 1 and 2 reflect successive years. Thus, $w_{i}$ winter reflects overwintering survivorship and/or emergence phenology, while $w_{i}$ summer reflects the population growth rate, including recruitment from diapause, of the $i$ th clone over the growing season. In analyses of variance on the fitness dynamics, all $w^{\prime}$ s were scaled through a $\log _{10}$-transformation.

All four clones were not present in all samples, due to limited sample sizes and/or late emergence of specific clones, especially in the early spring collections. To allow calculation of fitnesses for all clones, one individual of each clone was added to each 'incomplete' sample before calculating the frequencies. This causes an overestimation of the frequency of the less common clones, and when these measures are used to estimate the seasonal shift in fitness for the clones during the annual cycle, the amount of temporal variation in fitness will be conservatively underestimated. Clone frequencies, sample sizes 
and raw and transformed concentrations and diversities are presented in Appendix A, and the raw and $\log _{10^{-}}$ transformed fitnesses for all seasonal transitions are presented in Appendix B.

For testing significance of changes in both diversity and fitness between seasons and localities, we used generalized linear modelling procedures from SAS (1990, GLM procedure) and Superanova (Abacus, 1989).

For clonal diversity, there are only enough degrees of freedom to test the effects of locality, season, year and their two-way interactions. The ANOVA on transformed $D$ revealed significant main effects only for locality $(P=0.043)$ and season $(P=0.001)$; however, the overall model was not significant $(P=0.080)$. One problem in contrasting the different years is the unbalanced nature of the data since for 1981 and 1987, only autumn samples of clonal diversity were available, whereas year effects for '82, '83 '86 and '88 included pooled spring and autumn samples (Appendix A). We therefore treat different years as random samples of spring or autumn clonal diversities among the four localities and test for locality and seasonal effects and their interaction. For testing of pair-wise locality differences in diversity, we used Scheffé's (1959, p 55ff) $S$. This is one of the most conservative and robust of the pairwise post hoc tests, being insensitive to unequal sample sizes and heterogeneity of variances. Homogeneity of variances among samples was tested by the F-max test (Sokal and Rohlf, 1995).

\section{Results}

Temporal vs spatial components of diversity

One clone ('A') dominated in frequency in all populations and in all years. In some of the spring samples (eg, Barkåkra 82, Ljungbyhed 83 and Stenshuvud 86), virtually all flies were clone A. Figure 2 plots the frequencies of the different clones (after adjusting for missing clones) in the four populations over the course of the sampling period and illustrates the oscillatory behavior of clone frequency in these data.

Table 1 presents the simplified analysis of variance on D, after removing year as a factor (see Materials and methods, above). Interestingly, the strong effect of season $(P=0.0001)$ is manifested by an approximate $20 \%$ increase in diversity from spring to autumn at all localities (Figure 3). However, long-term diversities remained constant over the course of the sampling, as indicated by the preliminary ANOVA examining the year effect (see Materials and methods, above). At three of the localities, autumn 81 and autumn 88 diversities were similar, while at Stenshuvud, D increased from 0.31 in autumn 81 to 0.61 in autumn 88 (see Appendix A).

There is a weak $(P=0.024)$ main effect of locality on diversity, due to a single weak pair-wise difference between Smygeham and Lyngbyhed (Scheffé's $S=0.213$, $P=0.040)$. Extraction of the additive variance components for diversity (Sokal and Rohlf, 1995, p 333) reveals that over $82 \%$ of the total variance among samples is due to differences between seasons and only $15 \%$ is due to differences among localities.
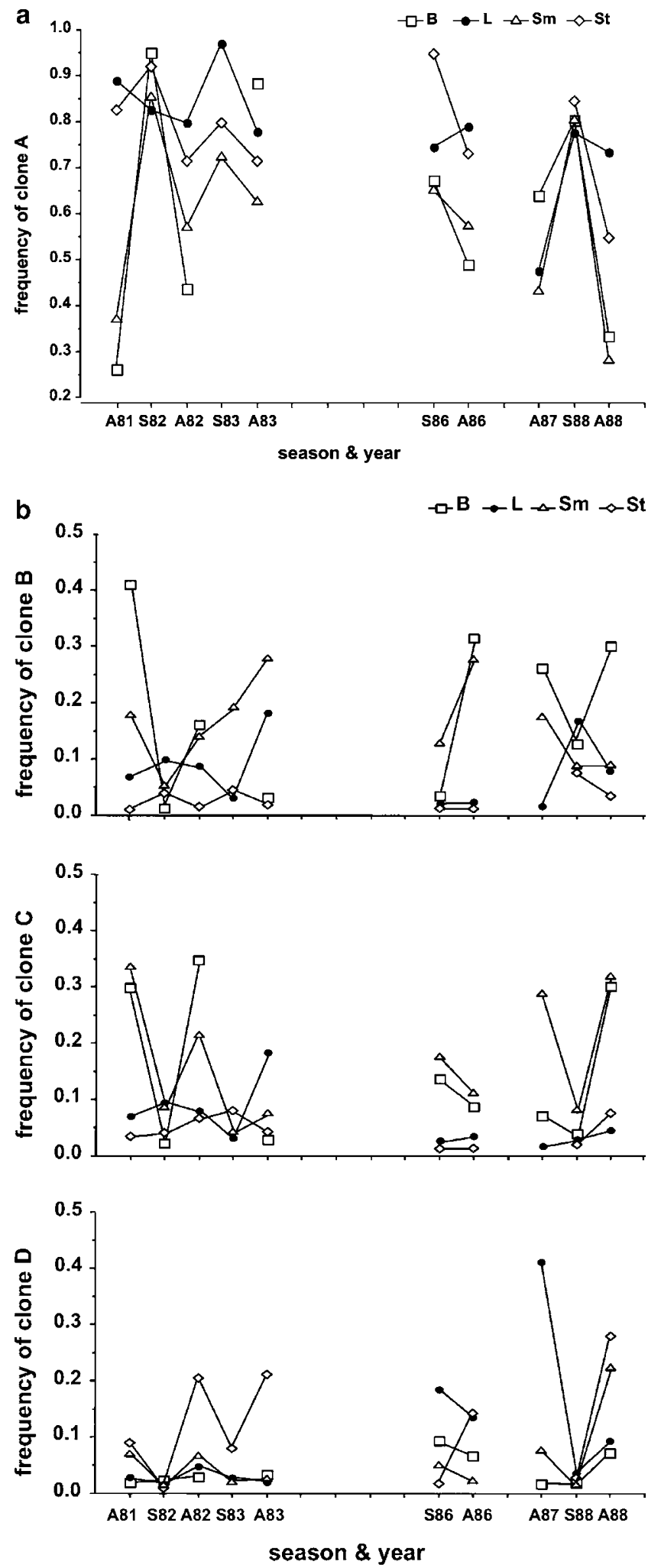

Figure 2 Fluctuating clone frequencies during the course of 8 years. (a) Changes in the most common clone, A. (b) Changes in clones B (top), C (middle) and D (bottom). Locality abbreviations are B Barkåkra; L - Ljungbyhed. St - Stenshuvud and Sm - Smygehamn. In all graphs, solid lines connect those autumn to spring and spring to autumn transitions over which fitnesses could be estimated. Note the absence of data for Barkåkra, spring 83 and Stenshuvud, autumn 87 due to lack of flies at those locations during collecting trips (see Appendix A). 
Table 1 Effects of season and locality and their interaction on clonal diversity

\begin{tabular}{lrccrc}
\hline Source & df & Sum of squares & Mean square & F-value & P-value \\
\hline Model & 7 & 0.830 & 0.119 & 4.92 & $\mathbf{0 . 0 0 0 9}$ \\
$\quad$ Season & 1 & 0.473 & 0.473 & 19.71 & $\mathbf{0 . 0 0 0 1}$ \\
Locality & 3 & 0.262 & 0.087 & 3.62 & $\mathbf{0 . 0 2 4 3}$ \\
$\quad$ Season $\times$ locality & 3 & 0.037 & 0.012 & 0.51 & 0.6808 \\
Error & 30 & 0.724 & 0.024 & &
\end{tabular}

Diversity measured as $D=1-\left(p_{i}\right)^{2}$ and transformed as arcsin(sqrt D) in radians. The $P$-values are the probability of a type I error. Model effects for which $P<0.05$ are given in bold.

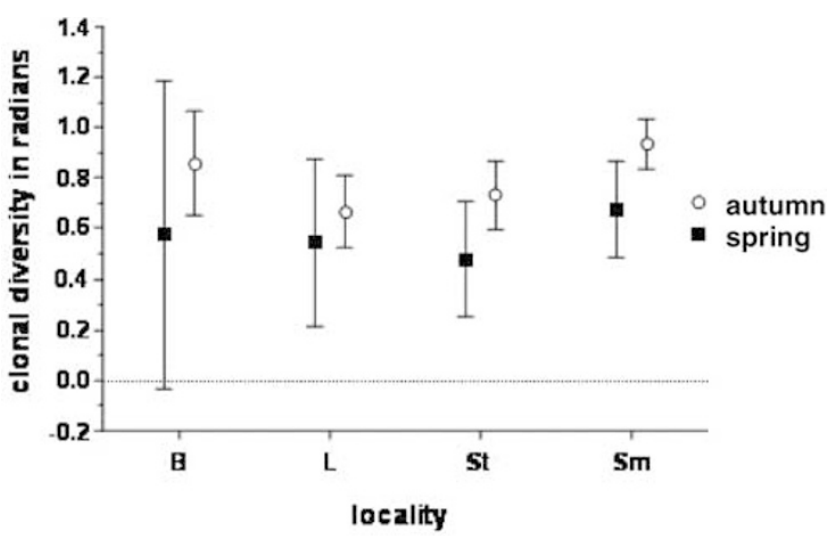

Figure 3 Seasonal changes in clonal diversity (in radians). Means among years $( \pm 95 \%$ confidence limits) are plotted for autumn (open circles) and spring (closed squares) samples. Locality abbreviations follow Figure 2: B - Barkåkra, L - Ljungbyhed. St Stenshuvud and Sm - Smygehamn. Numerical data in Appendix A.

\section{Clonal variation in fitness}

Table 2 presents the analysis of variance on logtransformed seasonal fitnesses. The fitness values for overwintering flies reflect the viability during adult overwintering and/or larval diapause of the clone along with timing of adult emergence, while the fitness values for the summer reflect a complex combination of traits including diapause phenology, fecundity, development rate, and viability. The only main effect that was significant was season, mean fitnesses increasing from winter to summer. However, this is simply an artifact of having only one of four clones (A) with mostly positive values during winter, while clones $B, C$ and $D$ all have mostly positive fitnesses in summer (Figure 4).

The homogeneity of the locality and clone main effects is a reflection of the fact that the frequencies of these four clones have remained relatively constant over the course of the sampling period. That is, there are no long-term increases in any of the clones among localities or years. The important effect is the interaction of clone by season, one of the two mechanisms by which deterministic maintenance of polymorphism can occur in clonal organisms. Figure 4 shows this interaction graphically, with the lines connecting sequential autumn-> spring$>$ autumn transitions for different year/locality combinations. Clones $\mathrm{C}$ and $\mathrm{D}$ show the most consistent increases in frequency over the growing season, while clone B increases in five of the season/locality transitions and decreases in the remaining five.
Table 2 Effect of locality, clone, season and their interactions on logtransformed fitnesses analyzed by a generalized linear factorial model (see Materials and methods)

\begin{tabular}{lrclcr}
\hline Source & df & Sum of squares & Mean square & F-value & P-value \\
\hline Model & 31 & 16.65 & 0.537 & 3.78 & $<\mathbf{0 . 0 0 0 1}$ \\
$\quad$ Season & 1 & 2.65 & 2.65 & 18.65 & $<\mathbf{0 . 0 0 0 1}$ \\
Locality & 3 & 0.25 & 0.083 & 0.586 & 0.6263 \\
Clone & 3 & 0.137 & 0.046 & 0.322 & 0.8093 \\
Clone $\times$ season & 3 & 4.267 & 1.422 & 10.01 & $<\mathbf{0 . 0 0 0 1}$ \\
Clone $\times$ locality & 9 & 0.691 & 0.077 & 0.54 & 0.8401 \\
Season $\times$ locality & 3 & 1.34 & 0.447 & 3.143 & $\mathbf{0 . 0 3 0 7}$ \\
C $\times$ S $\times$ L & 9 & 7.090 & 0.788 & 5.54 & $<\mathbf{0 . 0 0 0 1}$ \\
Error & 68 & 9.662 & 0.142 & & \\
\hline
\end{tabular}

$P$-values are the probability of a type I error. Model effects for which $P<0.05$ are given in bold.
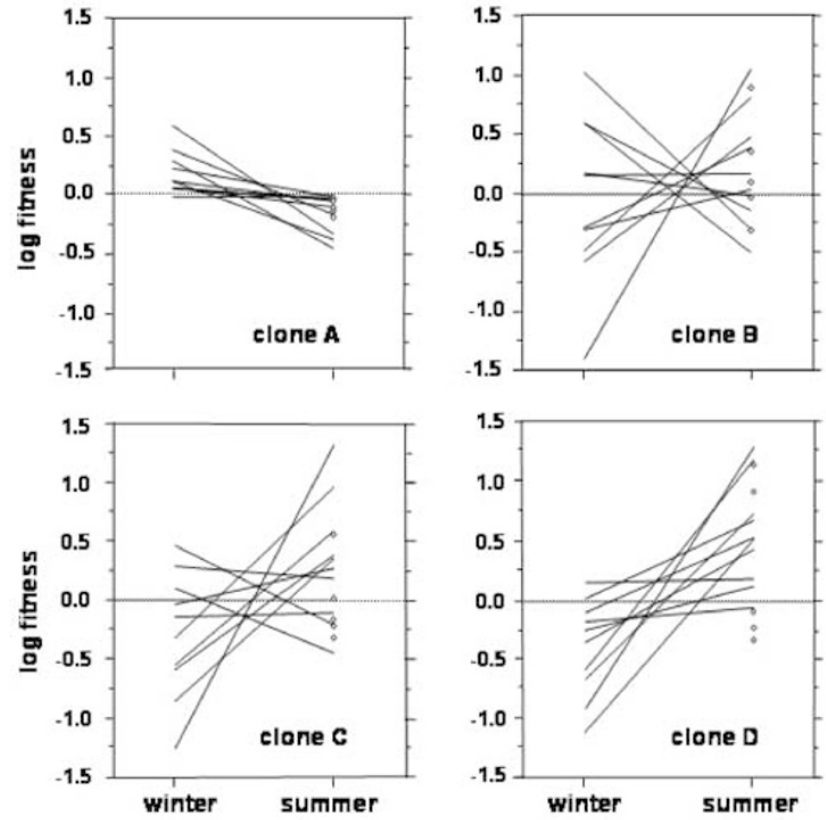

Figure 4 Interaction of seasonal fitnesses ( $\log _{10}$-transformed) among the four common clones. Lines connect those samples for which autumn-> spring->autumn transitions within a single locality were available, allowing calculation of sequential winter$>$ summer fitness changes for the four clones. Open diamonds indicate the five summer fitness estimates for which there were no preceding winter fitness estimates available due to lack of flies and/ or sampling during the previous autumn season. Numerical data in Appendix B.

\section{Discussion}

Temporal vs spatial components of diversity

The consistent and repeated increase in clonal diversity from spring to autumn among years and localities is an intriguing result. In the Rochester NY population of $D$. bifurcata, the frequency of the most common clone increased from July to August in 13 different subsamples from a $3 \mathrm{~km}^{2}$ area, including five samples collected in two successive years. In all these samples, clonal diversity and evenness declined during the month (Ochman et al, 1980). Since these authors did not sample in the early spring, it is difficult to compare their results directly with ours, other than emphasizing that the 
samples taken by Ochman et al in 1977 and 1978 still contained the four chromosome clones originally detected by Stalker (1956) from Rochester, arguing for some deterministic mechanism(s) maintaining long-term clonal diversity in North American populations of Dipsa.

In related studies, three obligately clonal (ie, nondiapausing) populations of the cladoceran, Daphnia magna, showed an increase in clonal evenness over the winter months and corresponding reduction in evenness during the summer months in two successive years (original data in Hebert and Ward, 1976, see Figure 2 in Parker, 1979).

Permanent (and presumably thelytokous) populations of the cladoceran, Daphnia magna (Hebert, 1974a,b) and nondiapausing (anholocyclic) populations of aphids (Tomiuk and Wöhrmann, 1984; Llewellyn et al, 2003) exhibit less genotypic diversity than diapausing (sexual) populations, suggesting that selection in asexual populations may be more intense than in sexual populations.

Carvalho and Crisp (1987) described a more complex situation in D. magna over a 1-year cycle (January to January) in which clonal diversity increased from January to midsummer and then declined again. Although the population which these authors monitored was a permanent lake, and hence subject mainly to thelytokous reproduction, two facts suggest that they indeed were dealing with sexual recruitment in their data. Firstly, although they failed to find any male individuals in their sampling from July 1981 to July 1983, females with ephippial (presumably sexual overwintering) eggs were found in some of their samples although never higher than $6 \%$. Secondly, these authors were unable to sample between February and May 1983, due to ice cover and the number of clones sampled jumped from 8 (their ' 3 locus' clones) to 17 between January and May 1983, strongly suggesting a pulse of sexual recruitment or emergence of previously dormant apomictic clones. However, as in our data here, a few clones (five in their case) dominated the collections and three of these showed seasonal cycling. More recently, Weeks and Hoffmann (1998) describe a similar case in three replicate populations of a thelyokous mite which show radical fluctuations in several clone frequencies over a 2-year sampling cycle. In this case, however, although some of the same clones were found in all populations, different clones were favored at the same time in the different populations, suggesting local adaptation by clones.

Taken together, these previous results support the general idea, originally suggested by Wright (1977, p 467ff), that selection in clonal mixtures should occur more rapidly than selection in sexual populations because of the greater proportion of genetic variance (ie dominance and epistatic components), which can be exposed to selection in obligate clonal populations.

Our data differ from those of Ochman et al (1980) in that diversity increases during the growing season, probably through differential timing of emergence from larval diapause and/or adult overwintering. Clone A is the first genotype to be active in the spring and so dominates early spring collections as old and worn adults. For the other clones, we conclude that either adults become active later or diapause larvae of these clones emerge and eclose later in the spring/early summer, increasing clonal diversity throughout the growing season.

\section{Clonal variation in fitness}

The most common clone shows a clear and consistent pattern in all years at all localities: the frequency change of clone A during overwintering is always positive compared to the change during the growing season. Clones $\mathrm{C}$ and $\mathrm{D}$ show the reverse pattern, while clone $\mathrm{B}$ gives a less consistent pattern (see Figures 2 and 4). As pointed out in the introduction, the clonal lineages that we followed in this study could themselves be genetically variable at hidden loci. One indication of such an effect would be that the same multi-locus genotype would not exhibit consistent fitness phenotypes among years or seasons. Thus, our clone B may represent two or more hidden clones, which respond individually to local or temporal environmental variation. An indication of this is that, of the six among-sample estimates of negative summer fitnesses for clone $B$, four of them were from the Stenshuvud population (Appendix B).

The four populations differ both in their clonal composition and in their mean clonal diversity, a variation which is associated with the degree of disturbance by mowing at the locality (Niklasson, 1995). In the two populations characterized by high clonal diversity, Barkåkra and Smygehamn, two of the clones, clone $\mathrm{B}$ and $\mathrm{C}$, show the same trend of high summer fitnesses every year, whereas clone D shows a consistent pattern at Barkåkra and Stenshuvud. These patterns and associations suggest some complex mixture of effects by abiotic and biotic factors affecting the fitness values of the clones. In contrast, clone $\mathrm{D}$ shows extremely high fitness values at all localities during the summer of 1988. The fact that this increase occurs in all the four populations at the same time while no such general increase occurred in clone $\mathrm{B}$ or $\mathrm{C}$ suggests that some abiotic factor specifically favorable to clone D was prevalent that summer. The summer of 1988 was warm and sunny and characterized by high temperatures especially in May and June. It can then be hypothesized that high temperatures promote the relative increase of clone D. An intriguing issue is in what manner the different clones respond to the various factors affecting the clone specific fitness values, an issue that at least in part might be solved by experimental studies.

\section{Behavioural response}

Christensen and Noer (1986) showed temporal variation between years in clone frequencies of the thelytokous race of the isopod Trichoniscus pusillus. Their results revealed a concordance in the frequency changes among sites suggesting a clonal adaptation to some major climatic fluctuation. Spatial variation and principal component analysis revealed differences in the presence of clones in different soil types and at different elevations, which was interpreted as clonal variation in tolerance to moisture conditions. The clone associated with dry environments also showed a significant increase after periods of severe drought, which further strengthened the hypothesis of clonal adaptation to different moisture conditions. This hypothesis was finally confirmed by an experimental study showing clonal variation in behavior in response to various moisture regimes (Christensen et al, 1988).

A difference in overwintering behaviour among clones could explain clone-specific winter fitness values in 
D. bifurcata. For example, if the dominant clone (A) has a stronger tendency to choose sheltered overwintering spots, or if it shows some behavioural response to decreasing temperature lacking in the other clones, then this might result in differences in survival.

\section{Physiological response}

Populations of Daphnia show both temporal variation in genotype frequencies and seasonal patterns of clonal variation. These frequency changes have been related both to biotic factors such as clonal composition, predator abundance, food concentration and to abiotic factors such as temperature, salinity, disturbance and light intensity. Carvalho (1987) showed in an experimental study that the 'seasonal clones' described by Carvalho and Crisp (1987) differed in their thermal response. The differences in survivorship and fecundity indicated that the clones were adapted to the temperatures prevalent during their respective season. Similar results were found in the obligate parthenogen ostracod Heterocypris incongruens where the clone that dominated in the natural population during winter showed an adaptation to lower temperatures (in the laboratory) than the clone that dominated during summer (Rossi and Menozzi, 1990).

Possible explanations for the different survival of $D$. bifurcata during overwintering are clonal variation in lethal threshold temperature for adults or in diapause tendency of larvae, which may provide an escape from selection over the winter. In the companion paper (Tomiuk et al, 2004), we show that clonal differences in diapause tendency can increase the parameter space for a stable polymorphism in a two-clone model with fluctuating fitnesses between seasons for the two clones.

In sum, the observed stable fluctuations in clone frequencies between seasons most likely reflect two qualitatively different selection regimes. In winter, selection may be dominated by viability during adult quiescence and differential diapause among the clones, while in summer, selection for a high intrinsic rate of increase dominates the clonal dynamics.

\section{Acknowledgements}

Per Dowes, Hugo Andersson, Sven-Axel Bengston and Marie Axelsson provided expert scientific advice and laboratory help to MN during her PhD work at Lund University. We collectively thank Koos Boomsma, Freddy Christiansen, John Jaenike and especially Conrad Istock for valuable comments on earlier versions of this paper. Additionally, this paper was improved greatly by the constructive criticisms of two anonymous reviewers. MN was supported in part by a grant from the Nordic Foundation (NorFA). JT was supported by travel grants from the European Science Foundation to visit the Department of Ecology and Genetics, University of Aarhus, Denmark.

\section{References}

Abacus Concepts (1989). SuperANOVA Version 1.11. Abacus Concepts, Inc: Berkeley, CA.

Anderson W, Dobzhansky Th, Pavlovsky O, Powell JR, Yardley D (1975). Three decades of genetic change in Drosophila pseudoobscura. Evolution 29: 24-36.
Andersson H (1970). Notes on North European Lonchoptera (Diptera: Lonchopteridae) with lectotype designations. Entomol Tid 91: 42-45.

Andersson H (1983). Taxonomisk flugforskning (Diptera). Teoretisk interessant praktiskt värdefull. Fauna och Flora 78: 157-164.

Annest JL, Templeton AR (1978). Genetic recombination and clonal selection in Drosophila mercatorum. Genetics 89: 193-210.

Asher JH (1970). Parthenogenesis and genetic variability. II. One-locus models for various diploid populations. Genetics 66: 369-391.

Baud F (1973). Biologie et cytologie de cinq espèces du genre Lonchoptera Meig. (Dipt.) dont l'une parthénogénétique et les autres bisexuées avec quelques remarques d'ordre taxonomique. Rev Suisse Zool 80: 473-515.

Carvalho GR (1987). The clonal ecology of Daphnia magna (Crustacea: Cladocera). II. Thermal differentiation among seasonal clones. J Anim Ecol 56: 469-478.

Carvalho GR, Crisp DJ (1987). The clonal ecology of Daphnia magna (Crustacea: Cladocera). I. Temporal changes in the clonal structure of a natural population. J Anim Ecol 56: 453-468.

Christensen B, Noer H (1986). Spatial and temporal components of genetic variation in triploid parthenogenetic Trichoniscus pusillus (Isopoda, Crustacea). Hereditas 105: 277-285.

Christensen B, Noer H, Theisen BF (1988). Differential response to humidity and soil type among clones of triploid parthenogenetic Trichoniscus pusillus (Isopoda, Crustacea). Hereditas 108: 213-217.

Coulson JC, Butterfield J (1982). The distribution and biology of Lonchopteridae (Diptera) in the upland regions of northern England. Ecol Entomol 7: 31-38.

Dobzhansky Th (1943). Temporal changes in the composition of populations of Drosophila pseudoobscura. Genetics 28: 162-186.

Dybdahl MF, Lively CM (1998). Host-parasite coevolution: evidence for rare advantage and time-lagged selection in a natural population. Evolution 52: 1057-1066.

Fager EW (1972). Diversity: a sampling study. Am Nat 106: 293-310.

Hebert PDN (1974a). Enzyme variability in natural populations of Daphnia magna. II. Genotypic frequencies in permanent populations. Genetics 77: 323-334.

Hebert PDN (1974b). Enzyme variability in natural populations of Daphnia magna. III. Genotypic frequencies in intermittent populations. Genetics 77: 335-341.

Hebert PDN, Crease TJ (1980). Clonal coexistence in Daphnia pulex (Leydig): another planktonic paradox. Science 207: 1363-1365.

Hebert PDN, Ward RD (1976). Enzyme variability in natural populations of Daphnia magna. IV. Ecological differentiation and frequency changes of genotypes at Audley End. Heredity 36: 331-341.

Jaenike J, Parker Jr ED, Selander RK (1980). Clonal niche structure in the parthenogenetic earthworm Octolasion tyrtaeum. Am Nat 116: 196-205.

Jokela J, Lively CM, Fox JA, Dybdahl MF (1997). Flat reaction norms and 'frozen' phenotypic variation in clonal snails (Potamopyrgus antipodarum). Evolution 51: 1120-1129.

Kimura M, Crow JF (1964). The number of alleles that can be maintained in a finite population. Genetics 49: 725-738.

Lawrence E (ed) (2000). Henderson's Dictionary of Biological Terms. 12th edn. Prentice Education Limited: Harlow, England.

Llewellyn KS, Loxdale HD, Harrington R, Brookes CP, Clark SJ, Sunnucks P (2003). Migration and genetic structure of the grain aphid (Sitobion avenae) in Britain related to climate and clonal fluctuation as revealed using microsatellites. Mol Ecol 12: 21-34.

Lushai G, Loxdale HD (2002). The biological improbability of a clone. Genet Res Camb 79: 1-9.

Lynch M, Gabriel W (1983). Phenotypic evolution and parthenogenesis. Am Nat 122: 745-764. 
Manly BFJ (1985). The Statistics of Natural Selection on Animal Populations. Chapman \& Hall: London.

Mitter C, Futuyma DJ, Schneider JC, Hare JD (1979). Genetic variation and host plant relations in a parthenogenetic moth. Evolution 33: 777-790.

Nei M (1987). Molecular Evolutionary Genetics. Columbia University Press: New York.

Niklasson M (1995). Clonal diversity and individual adaptability in two colonizing parthenogenetic insects. PhD Thesis. Lund University: Sweden.

Ochman H, Stille B, Niklasson M, Selander RK, Templeton AR (1980). Evolution of clonal diversity in the parthenogenetic fly Lonchoptera dubia. Evolution 34: 539-547.

Parker Jr ED (1979). Ecological implications of clonal diversity in parthenogenetic morphospecies. Am Zool 19: 753-762.

Poulik MD (1957). Starch gel electrophoresis in a discontinuous system of buffers. Nature 180: 1477-1479.

Rossi V, Menozzi P (1990). The clonal ecology of Heterocypris incongruens (Ostracoda). Oikos 57: 388-398.

SAS (1990). SAS/STAT User's Guide. Version 6, Volume 2, GLMVARCOMP. 4th edn. SAS Institute Inc.: Cary, NC, USA.

Scheffé H (1959). The Analysis of Variance. Wiley: New York.

Sebens KP, Thorne BL (1985). Coexistence of clones, clonal diversity, and the effects of disturbance. In Jackson JBC, Buss LW, Cook RE (eds) Population Biology and Evolution of Clonal Organisms. Yale University Press: New Haven, pp 357-398. Simpson ES (1949). Measurement of diversity. Nature 163: 688. Sokal RR, Rohlf FJ (1995). Biometry. 3rd edn. WH Freeman: San Francisco.

Stalker HD (1956). On the evolution of parthenogenesis in Lonchoptera (Diptera). Evolution 10: 345-359.

Templeton AR (1982). The prophecies of parthenogenesis. In Dingle H, Hegmann JP (eds) Evolution and Genetics of Life Histories. Springer-Verlag: New York, Heidelberg, Berlin, pp 75-101.
Tomiuk J, Niklasson M, Parker Jr ED (2004). Maintenance of clonal diversity in Dipsa bifurcata (Diptera: Lonchopteridae). II. Diapause stabilizes clonal coexistence. Heredity (in press).

Tomiuk J, Wöhrmann K (1981). Changes in genotype frequencies at the MDH-locus in populations of Macrosiphum rosae (L.) (Hem., Aphididae). Biol Zentralbl 100: 631-640.

Tomiuk J, Wöhrmann K (1984). Genotypic variability in natural populations of Macrosiphum rosae (L.) in Europe. Biol Zentralbl 103: 113-122.

Vrijenhoek RC (1978). Coexistence of clones in a heterogeneous environment. Science 199: 549-552.

Vrijenhoek RC (1979). Factors affecting clonal diversity and coexistence. Am Zool 19: 787-797.

Weeks AR, Hoffmann AA (1998). Intense selection of mite clones in a heterogeneous environment. Evolution 52: 1325-1333.

Wright S (1977). Evolution and the Genetics of Populations, Vol. 3. Experimental Results and Evolutionary Deductions. University of Chicago Press: Chicago, USA.

\section{Appendix A}

Samples, sample sizes, clone frequencies of the four common clones, pooled frequencies of any rare clones (if present) and raw and arcsine transformed clonal diversities (Table A.1)

\section{Appendix B}

Raw and $\log _{10}$ transformed fitnesses measured as the ratio of a clone's frequency in spring-autumn (summer fitnesses) and autumn-spring transitions (Table B.1).

Table A.1 Samples, sample sizes, clone frequencies of the four common clones, pooled frequencies of any rare clones (if present) and raw and arcsine transformed clonal diversities

\begin{tabular}{|c|c|c|c|c|c|c|c|c|c|c|c|}
\hline Locality & Season & Year & $p(A)$ & $p(B)$ & $p(C)$ & $p(D)$ & $p($ rare $)$ & Simpson's C & $D=(1-C)$ & $\arcsin ($ sqrt $D)$ in radians & $N$ \\
\hline Barkåkra & Autumn & 81 & 0.260 & 0.402 & 0.298 & 0.012 & 0.028 & 0.319 & 0.681 & 0.971 & 77 \\
\hline Barkåkra & Spring & 82 & 0.952 & 0.016 & 0.016 & 0.016 & 0.000 & 0.905 & 0.095 & 0.314 & 61 \\
\hline Barkåkra & Autumn & 82 & 0.437 & 0.161 & 0.345 & 0.023 & 0.034 & 0.338 & 0.662 & 0.951 & 87 \\
\hline Barkåkra & Autumn & 83 & 0.882 & 0.029 & 0.029 & 0.029 & 0.031 & 0.782 & 0.218 & 0.486 & 34 \\
\hline Barkåkra & Spring & 86 & 0.673 & 0.038 & 0.135 & 0.096 & 0.058 & 0.485 & 0.515 & 0.800 & 52 \\
\hline Barkåkra & Autumn & 86 & 0.490 & 0.306 & 0.092 & 0.061 & 0.051 & 0.349 & 0.651 & 0.939 & 196 \\
\hline Barkåkra & Autumn & 87 & 0.638 & 0.259 & 0.069 & 0.017 & 0.017 & 0.479 & 0.521 & 0.806 & 58 \\
\hline Barkåkra & Spring & 88 & 0.804 & 0.131 & 0.033 & 0.016 & 0.016 & 0.665 & 0.335 & 0.618 & 61 \\
\hline Barkåkra & Autumn & 88 & 0.333 & 0.300 & 0.300 & 0.067 & 0.000 & 0.295 & 0.705 & 0.996 & 30 \\
\hline Ljungbyhed & Autumn & 81 & 0.889 & 0.067 & 0.022 & 0.022 & 0.000 & 0.796 & 0.204 & 0.469 & 45 \\
\hline Ljungbyhed & Spring & 82 & 0.825 & 0.095 & 0.064 & 0.016 & 0.000 & 0.695 & 0.305 & 0.585 & 62 \\
\hline Ljungbyhed & Autumn & 82 & 0.798 & 0.089 & 0.040 & 0.048 & 0.025 & 0.649 & 0.351 & 0.634 & 124 \\
\hline Ljungbyhed & Spring & 83 & 0.907 & 0.031 & 0.031 & 0.031 & 0.000 & 0.941 & 0.059 & 0.244 & 32 \\
\hline Ljungbyhed & Autumn & 83 & 0.778 & 0.178 & 0.022 & 0.022 & 0.000 & 0.638 & 0.362 & 0.646 & 44 \\
\hline Ljungbyhed & Spring & 86 & 0.744 & 0.023 & 0.023 & 0.186 & 0.024 & 0.589 & 0.411 & 0.696 & 43 \\
\hline Ljungbyhed & Autumn & 86 & 0.788 & 0.029 & 0.025 & 0.144 & 0.014 & 0.643 & 0.357 & 0.640 & 278 \\
\hline Ljungbyhed & Autumn & 87 & 0.475 & 0.016 & 0.016 & 0.410 & 0.083 & 0.401 & 0.599 & 0.885 & 60 \\
\hline Ljungbyhed & Spring & 88 & 0.774 & 0.162 & 0.032 & 0.032 & 0.000 & 0.628 & 0.372 & 0.656 & 30 \\
\hline Ljungbyhed & Autumn & 88 & 0.732 & 0.081 & 0.049 & 0.089 & 0.049 & 0.555 & 0.445 & 0.730 & 123 \\
\hline Stenshuvud & Autumn & 81 & 0.824 & 0.009 & 0.037 & 0.093 & 0.037 & 0.690 & 0.310 & 0.590 & 108 \\
\hline Stenshuvud & Spring & 82 & 0.920 & 0.034 & 0.034 & 0.012 & 0.000 & 0.849 & 0.151 & 0.399 & 87 \\
\hline Stenshuvud & Autumn & 82 & 0.713 & 0.021 & 0.064 & 0.202 & 0.000 & 0.553 & 0.447 & 0.732 & 94 \\
\hline Stenshuvud & Spring & 83 & 0.795 & 0.041 & 0.082 & 0.082 & 0.000 & 0.649 & 0.351 & 0.634 & 49 \\
\hline Stenshuvud & Autumn & 83 & 0.714 & 0.029 & 0.029 & 0.206 & 0.022 & 0.554 & 0.446 & 0.731 & 34 \\
\hline Stenshuvud & Spring & 86 & 0.947 & 0.018 & 0.017 & 0.018 & 0.000 & 0.899 & 0.101 & 0.324 & 59 \\
\hline Stenshuvud & Autumn & 86 & 0.731 & 0.017 & 0.008 & 0.143 & 0.101 & 0.565 & 0.435 & 0.720 & 118 \\
\hline Stenshuvud & Spring & 88 & 0.843 & 0.078 & 0.020 & 0.020 & 0.039 & 0.719 & 0.281 & 0.558 & 50 \\
\hline Stenshuvud & Autumn & 88 & 0.547 & 0.038 & 0.075 & 0.283 & 0.057 & 0.390 & 0.610 & 0.897 & 53 \\
\hline
\end{tabular}

(Table A1 continued) 
Table A.1 Continued

\begin{tabular}{|c|c|c|c|c|c|c|c|c|c|c|c|}
\hline Locality & Season & Year & $p(A)$ & $p(B)$ & $p(C)$ & $p(D)$ & $p$ (rare) & Simpson's C & $D=(1-C)$ & $\arcsin (s q r t D)$ in radians & $N$ \\
\hline Smygeham & Autumn & 81 & 0.369 & 0.185 & 0.338 & 0.062 & 0.046 & 0.291 & 0.709 & 1.001 & 65 \\
\hline Smygeham & Spring & 82 & 0.852 & 0.049 & 0.086 & 0.012 & 0.001 & 0.736 & 0.264 & 0.540 & 81 \\
\hline Smygeham & Autumn & 82 & 0.570 & 0.140 & 0.206 & 0.056 & 0.028 & 0.391 & 0.609 & 0.895 & 107 \\
\hline Smygeham & Spring & 83 & 0.722 & 0.194 & 0.028 & 0.028 & 0.028 & 0.561 & 0.439 & 0.724 & 36 \\
\hline Smygeham & Autumn & 83 & 0.625 & 0.281 & 0.063 & 0.031 & 0.000 & 0.474 & 0.526 & 0.811 & 31 \\
\hline Smygeham & Spring & 86 & 0.650 & 0.125 & 0.175 & 0.050 & 0.000 & 0.471 & 0.529 & 0.814 & 40 \\
\hline Smygeham & Autumn & 86 & 0.573 & 0.286 & 0.104 & 0.026 & 0.011 & 0.422 & 0.578 & 0.864 & 192 \\
\hline Smygeham & Autumn & 87 & 0.431 & 0.172 & 0.293 & 0.069 & 0.035 & 0.307 & 0.693 & 0.983 & 58 \\
\hline Smygeham & Spring & 88 & 0.804 & 0.082 & 0.082 & 0.016 & 0.016 & 0.660 & 0.340 & 0.623 & 60 \\
\hline Smygeham & Autumn & 88 & 0.281 & 0.083 & 0.312 & 0.219 & 0.105 & 0.242 & 0.758 & 1.056 & 96 \\
\hline Average & & & 0.687 & 0.113 & 0.097 & 0.078 & 0.023 & & & & 2915 \\
\hline
\end{tabular}

Table B.1 Raw and $\log _{10}$ transformed fitnesses measured as the ratio of a clone's frequency in spring-autumn (summer fitnesses) and autumn-spring transitions

\begin{tabular}{|c|c|c|c|c|}
\hline \multirow[t]{2}{*}{ Locality } & \multirow[t]{2}{*}{ Season $\mathcal{E}$ year } & \multirow[t]{2}{*}{ Clone } & \multicolumn{2}{|c|}{ Fitnesses } \\
\hline & & & Raw & $\log$ \\
\hline Barkåkra & Winter 81-82 & A & 3.6607 & 0.5636 \\
\hline Barkåkra & Winter $87-88$ & A & 1.2596 & 0.1002 \\
\hline Ljungbyhed & Winter 81-82 & A & 0.9288 & -0.0321 \\
\hline Ljungbyhed & Winter $82-83$ & A & 1.1102 & 0.0454 \\
\hline Ljungbyhed & Winter $87-88$ & A & 1.6296 & 0.2121 \\
\hline Stenshuvud & Winter 81-82 & A & 1.1165 & 0.0479 \\
\hline Stenshuvud & Winter $82-83$ & A & 1.1164 & 0.0478 \\
\hline Smygeham & Winter $81-82$ & A & 2.3089 & 0.3634 \\
\hline Smygeham & Winter 82-83 & A & 1.2667 & 0.1027 \\
\hline Smygeham & Winter $87-88$ & A & 1.8645 & 0.2706 \\
\hline Barkåkra & Summer 82 & A & 0.4596 & -0.3376 \\
\hline Barkåkra & Summer 86 & A & 0.7281 & -0.1378 \\
\hline Barkåkra & Summer 88 & A & 0.4144 & -0.3826 \\
\hline Ljungbyhed & Summer 82 & A & 0.9665 & -0.0148 \\
\hline Ljungbyhed & Summer 83 & A & 0.8782 & -0.0564 \\
\hline Ljungbyhed & Summer 86 & $\mathrm{~A}$ & 1.0595 & 0.0251 \\
\hline Ljungbyhed & Summer 88 & A & 0.9455 & -0.0243 \\
\hline Stenshuvud & Summer 82 & A & 0.7750 & -0.1107 \\
\hline Stenshuvud & Summer 83 & A & 0.8970 & -0.0472 \\
\hline Stenshuvud & Summer 86 & A & 0.7713 & -0.1128 \\
\hline Stenshuvud & Summer 88 & $\mathrm{~A}$ & 0.6488 & -0.1879 \\
\hline Smygeham & Summer 82 & A & 0.6690 & -0.1746 \\
\hline Smygeham & Summer 83 & A & 0.8654 & -0.0628 \\
\hline Smygeham & Summer 86 & A & 0.8815 & -0.0548 \\
\hline Smygeham & Summer 88 & A & 0.3497 & -0.4563 \\
\hline Barkåkra & Winter 81-82 & B & 0.0409 & -1.3883 \\
\hline Barkåkra & Winter $87-88$ & B & 0.5135 & -0.2894 \\
\hline Ljungbyhed & Winter 81-82 & B & 1.4478 & 0.1607 \\
\hline Ljungbyhed & Winter 82-83 & B & 0.3258 & -0.4870 \\
\hline Ljungbyhed & Winter 87-88 & B & 10.1008 & 1.0044 \\
\hline Stenshuvud & Winter 81-82 & B & 3.7778 & 0.5772 \\
\hline Stenshuvud & Winter $82-83$ & B & 3.7273 & 0.5714 \\
\hline Smygeham & Winter $81-82$ & B & 0.2649 & -0.5770 \\
\hline Smygeham & Winter 82-83 & B & 1.3857 & 0.1417 \\
\hline Smygeham & Winter $87-88$ & $\mathrm{~B}$ & 0.4826 & -0.3165 \\
\hline Barkåkra & Summer 82 & B & 9.4706 & 0.9764 \\
\hline Barkåkra & Summer 86 & B & 8.0526 & 0.9059 \\
\hline Barkåkra & Summer 88 & B & 2.2932 & 0.3604 \\
\hline Ljungbyhed & Summer 82 & B & 0.9323 & -0.0304 \\
\hline Ljungbyhed & Summer 83 & B & 6.1287 & 0.7874 \\
\hline Ljungbyhed & Summer 86 & B & 1.2609 & 0.1007 \\
\hline Ljungbyhed & Summer 88 & B & 0.5012 & -0.3000 \\
\hline Stenshuvud & Summer 82 & B & 0.3235 & -0.4901 \\
\hline
\end{tabular}


Table B.1 Continued

\begin{tabular}{|c|c|c|c|c|}
\hline \multirow[t]{2}{*}{ Locality } & \multirow[t]{2}{*}{ Season $\mathcal{E}$ year } & \multirow[t]{2}{*}{ Clone } & \multicolumn{2}{|c|}{ Fitnesses } \\
\hline & & & Raw & $\log$ \\
\hline Stenshuvud & Summer 83 & B & 0.7073 & -0.1504 \\
\hline Stenshuvud & Summer 86 & B & 0.9365 & -0.0285 \\
\hline Stenshuvud & Summer 88 & B & 0.4845 & -0.3147 \\
\hline Smygeham & Summer 82 & B & 2.8571 & 0.4559 \\
\hline Smygeham & Summer 83 & B & 1.4481 & 0.1608 \\
\hline Smygeham & Summer 86 & B & 2.2880 & 0.3595 \\
\hline Smygeham & Summer 88 & B & 1.0167 & 0.0072 \\
\hline Barkåkra & Winter $81-82$ & $\mathrm{C}$ & 0.0537 & -1.2701 \\
\hline Barkåkra & Winter $87-88$ & $\mathrm{C}$ & 0.4783 & -0.3203 \\
\hline Ljungbyhed & Winter 81-82 & $\mathrm{C}$ & 2.9545 & 0.4705 \\
\hline Ljungbyhed & Winter $82-83$ & C & 0.7250 & -0.1397 \\
\hline Ljungbyhed & Winter $87-88$ & $\mathrm{C}$ & 1.9412 & 0.2881 \\
\hline Stenshuvud & Winter $81-82$ & $\mathrm{C}$ & 0.9189 & -0.0367 \\
\hline Stenshuvud & Winter $82-83$ & $\mathrm{C}$ & 1.2813 & 0.1076 \\
\hline Smygeham & Winter 81-82 & $\mathrm{C}$ & 0.2544 & -0.5944 \\
\hline Smygeham & Winter $82-83$ & $\mathrm{C}$ & 0.1359 & -0.8667 \\
\hline Smygeham & Winter $87-88$ & $\mathrm{C}$ & 0.2786 & -0.5550 \\
\hline Barkåkra & Summer 82 & $\mathrm{C}$ & 20.9821 & 1.3218 \\
\hline Barkåkra & Summer 86 & $\mathrm{C}$ & 0.6815 & -0.1665 \\
\hline Barkåkra & Summer 88 & C & 9.0909 & 0.9586 \\
\hline Ljungbyhed & Summer 82 & $\mathrm{C}$ & 0.6250 & -0.2041 \\
\hline Ljungbyhed & Summer 83 & $\mathrm{C}$ & 0.7586 & -0.1200 \\
\hline Ljungbyhed & Summer 86 & $\mathrm{C}$ & 1.0870 & 0.0362 \\
\hline Ljungbyhed & Summer 88 & $\mathrm{C}$ & 1.5343 & 0.1859 \\
\hline Stenshuvud & Summer 82 & C & 1.8824 & 0.2747 \\
\hline Stenshuvud & Summer 83 & $\mathrm{C}$ & 0.3537 & -0.4514 \\
\hline Stenshuvud & Summer 86 & $\mathrm{C}$ & 0.4706 & -0.3274 \\
\hline Stenshuvud & Summer 88 & $\mathrm{C}$ & 3.7500 & 0.5740 \\
\hline Smygeham & Summer 82 & C & 2.3953 & 0.3794 \\
\hline Smygeham & Summer 83 & C & 2.2489 & 0.3520 \\
\hline Smygeham & Summer 86 & C & 0.5943 & -0.2260 \\
\hline Smygeham & Summer 88 & $\mathrm{C}$ & 3.8217 & 0.5823 \\
\hline Barkåkra & Winter 81-82 & $\mathrm{D}$ & 1.3333 & 0.1249 \\
\hline Barkåkra & Winter $87-88$ & $\mathrm{D}$ & 0.9412 & -0.0263 \\
\hline Ljungbyhed & Winter 81-82 & $\mathrm{D}$ & 0.7273 & -0.1383 \\
\hline Ljungbyhed & Winter $82-83$ & $\mathrm{D}$ & 0.6042 & -0.2188 \\
\hline Ljungbyhed & Winter $87-88$ & $\mathrm{D}$ & 0.0780 & -1.1078 \\
\hline Stenshuvud & Winter 81-82 & $\mathrm{D}$ & 0.1183 & -0.9271 \\
\hline Stenshuvud & Winter $82-83$ & D & 0.4059 & -0.3915 \\
\hline Smygeham & Winter 81-82 & $\mathrm{D}$ & 0.1935 & -0.7132 \\
\hline Smygeham & Winter $82-83$ & $\mathrm{D}$ & 0.5000 & -0.3010 \\
\hline Smygeham & Winter $87-88$ & $\mathrm{D}$ & 0.2319 & -0.6347 \\
\hline Barkåkra & Summer 82 & $\mathrm{D}$ & 1.4375 & 0.1576 \\
\hline Barkåkra & Summer 86 & $\mathrm{D}$ & 0.6354 & -0.1969 \\
\hline Barkåkra & Summer 88 & D & 4.1875 & 0.6220 \\
\hline Ljungbyhed & Summer 82 & $\mathrm{D}$ & 3.0000 & 0.4771 \\
\hline Ljungbyhed & Summer 83 & $\mathrm{D}$ & 0.7586 & -0.1200 \\
\hline Ljungbyhed & Summer 86 & $\mathrm{D}$ & 0.7745 & -0.1110 \\
\hline Ljungbyhed & Summer 88 & $\mathrm{D}$ & 2.7813 & 0.4442 \\
\hline Stenshuvud & Summer 82 & $\mathrm{D}$ & 18.3636 & 1.2640 \\
\hline Stenshuvud & Summer 83 & $\mathrm{D}$ & 2.5122 & 0.4001 \\
\hline Stenshuvud & Summer 86 & $\mathrm{D}$ & 7.9328 & 0.8994 \\
\hline Stenshuvud & Summer 88 & $\mathrm{D}$ & 14.1500 & 1.1508 \\
\hline Smygeham & Summer 82 & $\mathrm{D}$ & 4.6667 & 0.6690 \\
\hline Smygeham & Summer 83 & D & 1.1071 & 0.0442 \\
\hline Smygeham & Summer 86 & $\mathrm{D}$ & 0.5200 & -0.2840 \\
\hline Smygeham & Summer 88 & $\mathrm{D}$ & 13.6875 & 1.1363 \\
\hline
\end{tabular}

